\title{
Evaluating the impact of information and communication technologies on network reliability
}

DOI:

10.1109/MELCON.2016.7495313

\section{Document Version}

Submitted manuscript

Link to publication record in Manchester Research Explorer

\section{Citation for published version (APA):}

Cruzat Hermosilla, C., Kopsidas, K., \& Liu, S. (2016). Evaluating the impact of information and communication technologies on network reliability. In 18th IEEE Mediterranean Electrotechnical Conference (MELECON) (pp. 17). IEEE. https://doi.org/10.1109/MELCON.2016.7495313

\section{Published in:}

18th IEEE Mediterranean Electrotechnical Conference (MELECON)

\section{Citing this paper}

Please note that where the full-text provided on Manchester Research Explorer is the Author Accepted Manuscript or Proof version this may differ from the final Published version. If citing, it is advised that you check and use the publisher's definitive version.

\section{General rights}

Copyright and moral rights for the publications made accessible in the Research Explorer are retained by the authors and/or other copyright owners and it is a condition of accessing publications that users recognise and abide by the legal requirements associated with these rights.

\section{Takedown policy}

If you believe that this document breaches copyright please refer to the University of Manchester's Takedown Procedures [http://man.ac.uk/04Y6Bo] or contact uml.scholarlycommunications@manchester.ac.uk providing relevant details, so we can investigate your claim.

\section{OPEN ACCESS}




\title{
Evaluating the Impact of ICTs on Network Reliability
}

\author{
C. Cruzat, K. Kopsidas, S. Liu \\ School of Electrical and Electronic Engineering \\ University of Manchester \\ Manchester, UK
}

\begin{abstract}
Utilities' main drive is to provide economic, reliable and high quality electrical power to customers. At the same time, they also aim to enable the connection of continuously increasing renewable energy sources as efficiently as possible in order to assist the de-carbonization of the electricity sector. These challenges increase the power flows in a power network which requires further reinforcement and optimization. To address the increased power flow, smart grids are implemented utilizing more information and communication technologies (ICTs). This paper investigates the impact of such ICTs on the network via the inclusion of Time Varying Line Rating (TVLR) ICT. Thus, it introduces a holistic network-component design methodology, based on Sequential Monte Carlo, which allows investigating the impact of ICT failures on a network's reliability, with branches that employ TVLR. A study on the IEEE-RTS 96 network indicates that TVLR-ICT failures increase the interruption frequency of load reducing its overall quality of supply.
\end{abstract}

Keywords-Time Varying Line Rating, ICTs, Sequential Monte Carlo, OHL, Reliability, UGC.

\section{INTRODUCTION}

The increasing penetration of renewable energy generation has raised a significant need to find new techniques to improve the utilization and efficiency of the existing power transmission and distribution network assets. This requires a more responsive, reliable and flexible system in order to transmit these new sources of generation efficiently. Thus, to maintain the continuity of power supply, digital technologies will play a key role to provide automated monitoring, control and protection tools [1]. From these challenges, the network transmission and distribution capacities are the most difficult to address due to the high costs of network reinforcements and other social constraints.

In order to cope with these challenges power networks are becoming smarter [2]. This can be accomplished only with the assistance of information and communication technologies (ICTs) [1]. ICTs are responsible for capturing, measuring and processing the system parameters needed to control the system under normal and abnormal operation. Thus, the system operator is increasingly dependent on ICTs.

However the implementation of ICTs within power systems will inevitably have an impact on the network reliability. The security of a power system may be jeopardized by potential ICT failures [3]. Therefore it is of significant importance to understand and identify the ways in which ICT failures can compromise network reliability and to be able to quantify their impact [4].

Many reliability studies have considered the impact of smart grid technologies to improve the network reliability [3, 5, 6], however not much attention has been paid on the impact of these technologies on the power network reliability considering the failures of their ICTs [5]. Many studies consider the benefit of Time Varying Line Rating (TVLR) on Overhead Lines (OHLs) and Underground Cables (UGCs) on power system reliability $[6,7]$. However most of these studies do not consider the effects of failures and unreliability of their ICTs and their associated risk.

This paper presents a methodology that captures the effect of ICT failures on TVLR OHLs and UGCs networks on power systems. Consequently, the network branches components (OHLs and UGCs) are modelled in such a way so their key design properties are considered and controlled by the TVLRICT. Furthermore, this methodology is implemented to identify the impact of ICT failures.

\section{BACKGROUND}

Effective approaches to overcome thermal constraints in power networks without reinforcing the network include the implementation of TVLR technologies on UGCs and OHLs with the help of ICTs [8-10]. However, ICTs are prone to failures and such events may affect the TVLR operation as well. Therefore, ICT failures of TVLR-operated lines can affect the line rating and they therefore will reduce the system operator flexibility.

TVLR of OHLs can mainly be calculated through indirect and direct methods. The indirect TVLR method is solely based on weather data recorded from weather station nearby the OHLs [11]. This method is less accurate but requires less ICTs as well. The direct method measures data obtained directly from OHLs to calculate dynamic current rating of the OHLs, which requires the direct measurement of either conductor temperature (Temperature-based model) or the tension or sag (Sag-Tension based model) resulting in a more ICT-intensive TVTR system [12].

TVLR of UGCs is implemented through real-time condition monitoring of cables. Distributed temperature sensors can provide accurate measurements of cable surface temperatures along the cable which are used to compute their maximum (time-dependent) ampacity [13]. Other methods 
require measurements of soil temperature and conditions through nearby weather stations.

\section{RELIABILITy EVALUATION FRAMEWORK OF ICT ON POWER NETWORKS}

The proposed methodology is developed in order to allow modelling of the network components that incorporate TVLR ICT. It is realized in two distinct levels: The first is based on the network reliability modelling which is defined by the network properties and the second involves implementing OHLs and UGCs TVLR modelling that includes ICTs.

\section{A. Network Reliability Modelling}

The impact of ICT failures on TVLR for both OHL and UGC networks is captured through various network performance and ICT performance indices which are calculated with the methodology outlined here. The methodology for modelling the network reliability that considers ICTs within the UGCs and OHLs is divided into six different stages. These highlight the most significant tasks required to be executed as illustrated in Fig. 1 and are detailed in the following sections.

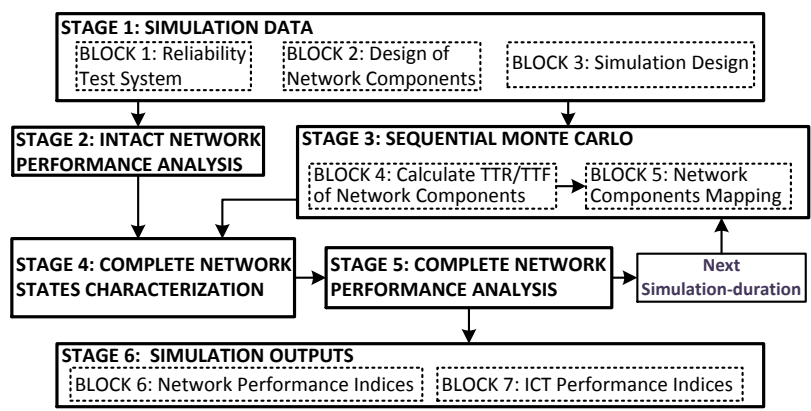

Fig. 1. Calculation flow of network flexibility/reliability and OHL ageing

1) Stage 1: The Simulation Data stage containts all imput data and implements the intial intact network calcualtions. These input data are devided in 3 blocks.

Block 1: Contains the data of the reliability test network. This includes data such as failures $(\lambda)$ and repair $(\mu)$ rates, of the branch components that are considered to fail (i.e., OHL, UGC and ICTs). In addition, the network configuration as well as the generation constraints and loading profiles are contained in this block.

Block 2: The data regarding the modelling of the branch components (OHLs \& UGCs) i.e. conductor technology, size and resistance inter alia are defined is this block. The weather data, that is used for both OHLs and UGCs and is required for the calculation of their line rating (thermal and current) modelling. To simplify this simulation procedure the modelling considers the same weather conditions for the entire network.

Block 3: The simulation design parameters define the steptime, analysis-duration and simulation-time. The step-time determines the segmentation of the time domain (i.e. minutes, hours, etc.) used to calculate network load profiles, weather profiles and the branch component rating modelling. The analysis-duration refers to the time frame (e.g. months, seasons, years, etc.) the reliability assessment is performed. In this case analysis-duration is annual. Simulation-time is defined by the desired accuracy of the output data (i.e., total number of simulations). In addition, the system load profile and branch components weather profile are created here.

2) Stage 2: The intact network performance analysis assesses the network as $100 \%$ reliable. Therefore, no failures occur during this assessment. The principal purpose of this stage is avoiding future Optimal Power Flow (OPF) calculations when intact states occur within the system and it, therefore, speeds up the simulation time.

3) Stage 3: Sequential Monte Carlo (SMC) method is applied here to develop the transition history of branch components. This allows capturing the failures duration and frequency. SMC technique is summarized in Block 4 and 5.

Block 4: The computations here build the transition history of network's branch (OHLs, UGCs and ICTs) components from normal state to failure state based on time to fail and time to repair (TTF/TTR) variables [14].

Block 5: The output annual sequential mapping of failures and repairs is developed for each branch prone to fail (i.e. OHLs, UGCs and ICTs).

4) Stage 4: This stage perfoms the hourly network states characterization as intact or non-intact. Thereby, the transition states mapping of the branches components annually provided by Stage 3 are used to hourly assess whether or not an AC OPF is needed (to obtain the system thermal and electrical parameters). When the network is characterised as intact for a step-time, intact network data from Stage 2 are utilized to provide the system thermal and electrical parameters (e.g. current, voltage, apparent power, etc.). Conversely, when the network is characterised as non-intact then Stage 4 directs to Stage 5.

5) Stage 5: The input values from Stage-4 are used to determine the network AC OPF status by implementing both thermal and electrical parameters prior to moving to the next step-time. Consequently Stage-5 perfoms calculations only during the non-intact step-times for the complete simulationduration. When the desired covariance is not achieved in Stage 5 a new 'next simulation-duration' starts. In addition, the network performance and ICTs metrics (discussed in previous section) are captured in this stage. It should also be noted that the conductor resistance at every step-time is calculated based on the line loading resulted from the AC OPF.

6) Stage 6: This is the final stage of the calcuations. Once the simulation-duration is completed (i.e., the Stage 5 loop is finished), the final indices are produced from those that have been recorded in Stage 5. Thus the generation of indices distributions that describe the complete network analysis is performed here. These outputs are summarised as the network performance and ICT performance indices. These are the Expected Network Annual Losses (ENAL), Expected Duration Load Curtailment (EDLC), Expected Frequency of 
Load Curtailment (EFLC), Expected Frequency Line Failures (EFLF), Expected Frequency ICT Failures (EFICTF) and Expected Energy not Supplied (EENS).

\section{B. ICT Modelling of OHLs and UGCs TVLR Systems}

The modelling of the ICT is realized in Stage- 3 of the computational framework (Fig. 1). This allows the ICT implementation to be considered in the modelling as an integral part of the network and its failure will have a specified output effect on the network performance. The ICT is integrated within the TVLR instrumentation on both OHLs and UGCs. Thus the ICTs are defined as TVLR-ICT $\mathrm{OHL}_{\mathrm{OH}}$ and TVLR$\mathrm{ICT}_{\mathrm{UGC}}$. The detailed modelling that illustrates this ICT technology integration within the (OHL \& UGCs) components is depicted with the flowchart in Fig 2. This TVLR-ICT model is divided into the input data, the modelling states, and the output data.

1) Input Data: These include the UGCs and OHLs rating information and inputs related to an individual ICT system.

a) UGC Rating Data: This block contains the UGC design specifications (i.e., UGCs type, size, laying conditions and soil temperature). The data are provided from Block 2 (Stage 1) and are used to define the maximum UGC rating.

b) OHL Rating Data: This block contains the OHL design characteristics, including conductor properties (type, diameter, resistence, maximum allowable temperature) and weather data (wind speed and direction, ambient temperature and solar radiation) needed to calculate the rating of the OHLs. The data are provided from Block 2 (Stage 1) therefore are already processed on the step-time increment selected in Block 3 (Stage 1).

c) ICT Component Data: This descibes the failure and repair rates of the ICT components which are used to describe the quality of the ICTs utilized.

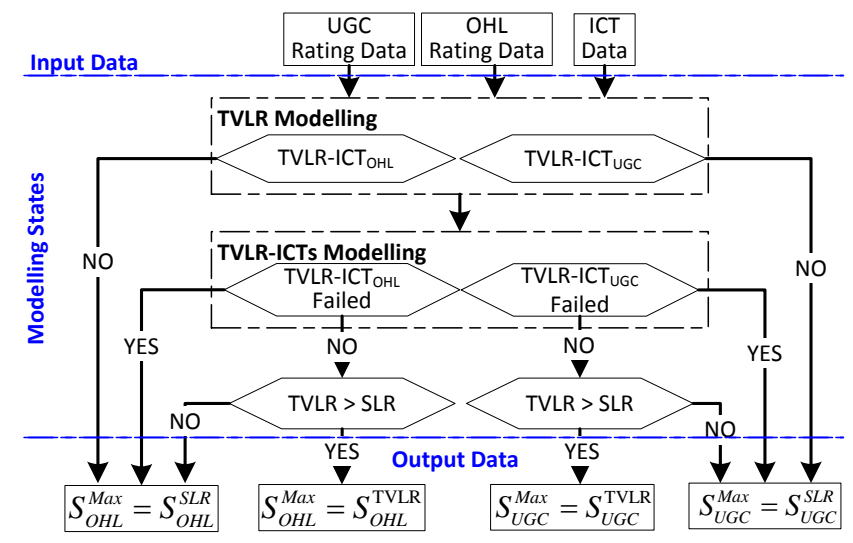

Fig. 2. ICT Implementation flowchart.

2) Modelling States: The barches on the network are modelled based on two states: the traditional one defined as TVLR and a more advanced one defined as TVLR-ICT which considers the inclusion of ICTs (Fig. 2).

a) TVLR Modelling: The calculations utilized for both the static rating of OHLs $\left(\mathrm{SLR}_{\mathrm{OHL}}\right)$ and $\mathrm{TVLR}_{\mathrm{OHL}}$ are implemented according to [15]. The (1) is used to evaluate the
OHL rating, which is dependent on the convective heat loss $q_{c}(t)$, radiated heat loss $q_{r}(t)$, solar heat gain $q_{s}(t)$ and conductor electrical resistance $R\left(T_{\text {pre-timestep }}\right)$. These are determined by the weather data segmented in step-times defined in Block 3 (Stage 1). It should also be noted that the conductor resistance is based on actual conductor temperature calculated on the previous step-time AC OPF (in Stage 5).

$$
I_{\text {OHL }}(t)=\sqrt{\left(q_{c}(t) \cdot q_{r}(t)-q_{s}(t)\right) /\left(R\left(T_{\text {pre-time.step }}\right)\right)}
$$

The calculations for the static rating of cables, the SLR $_{\mathrm{UGC}}$ and TVLR $_{U G C}$, are calculated with the steady state thermal model for buried cables shown in Fig. 3, according to the IEC Standard 60287-1 [16]. $\theta_{\mathrm{c}}, \theta_{\mathrm{s}}$, and $\theta_{\mathrm{a}}$ are the conductor, sheath and soil temperatures, respectively. $\mathrm{W}_{\mathrm{c}}, \mathrm{W}_{\mathrm{d}}, \mathrm{W}_{\mathrm{s}}, \mathrm{W}_{\mathrm{a}}$ represent the dielectric, screen and armor losses, correspondingly. $\mathrm{T}_{1}$ and $\mathrm{T}_{2}$ are the thermal resistances between conductor and sheath, and sheath and armor. $\mathrm{T}_{3}$ and $\mathrm{T}_{4}$ are the thermal resistances of the external jacket and the outer surroundings, respectively. The conductor temperature rise above $\theta_{\mathrm{a}}$ can be calculated by solving the thermal circuit (Fig. 3), while the current $\mathrm{I}_{\mathrm{UGC}}$ that results in that temperature rise can be derived from (2) where $\lambda_{1}$ is the sheath loss factor and $\lambda_{2}$ is the armor loss factor.

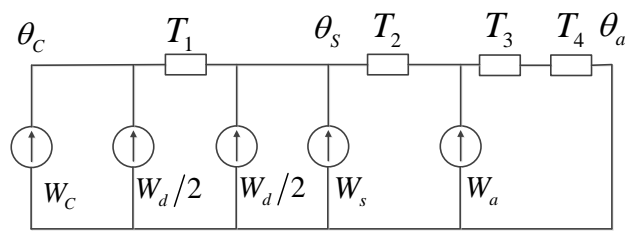

Fig. 3. Thermal Circuit Model of a Single Core Cable

$$
I_{U G C}=\sqrt{\left[\frac{\left(\theta_{c}-\theta_{a}\right)-W_{d}\left[0.5 T_{1}+\left(T_{2}+T_{3}+T_{4}\right)\right]}{R T_{1}+R\left(1+\lambda_{1}\right) T_{2}+R\left(1+\lambda_{1}+\lambda_{2}\right)\left(T_{3}+T_{4}\right)}\right]}
$$

b) TVLR-ICT Modelling: This defines the thermal rating of the brach components (OHL \& UGC) while also considering the ICT. In this case the TVLR-ICTs of UGC or OHLs influence the transition history of the complete network as each ICT within the network is generated following the procedure in Stage 3 (Fig. 1). The transition history of the ICTs is combined with the OHL and UGC rating data to provide the calculated TVLR output of each branch component when the ICT is in the operating state or utilize the SLR for the lines with the ICT being in the failure state (as shown in Fig 2).

3) Output Data: The TVLR-ICT model for both OHLs and UGCs provides the ampacities for all the branch components at every step-time increment troughout the analysis-duration. These line ampacities are implemented in Stage 5 of the methodology (Fig. 1) to permit the improved modelling of the network that captures the ICT failures.

\section{Application Of The Methodology}

The methodology is implemented on IEEE-RTS 96 (Fig. 4) considering the data in [17] with $1.4 \mathrm{pu}$ demand to stress the network and allowing for harnessing the flexibility in transmission capacity that is provided from the TVLR systems. 
The output capacity of the generators is also increased to $1.4 \mathrm{pu}$. Only lines (OHL \& UGC) and TVLR-ICT failures are considered in the simulation while generators are considered $100 \%$ reliable.

\section{A. OHL and UGC Data}

The two areas (low and high voltage) of the IEEE-RTS are considered to model the OHLs network with All Aluminum Alloy Conductors (AAAC). The low voltage section (138kV) utilizes Upas conductor and the $230 \mathrm{kV}$ area (high voltage) uses Araucaria. Their principal properties are shown in Table I. SLR is considered using Table I data and the parameters obtained from [15]. TVLR utilizes the weather parameters of year 2014 obtained from the Withworth Meteorological Observatory at the University of Manchester [18].

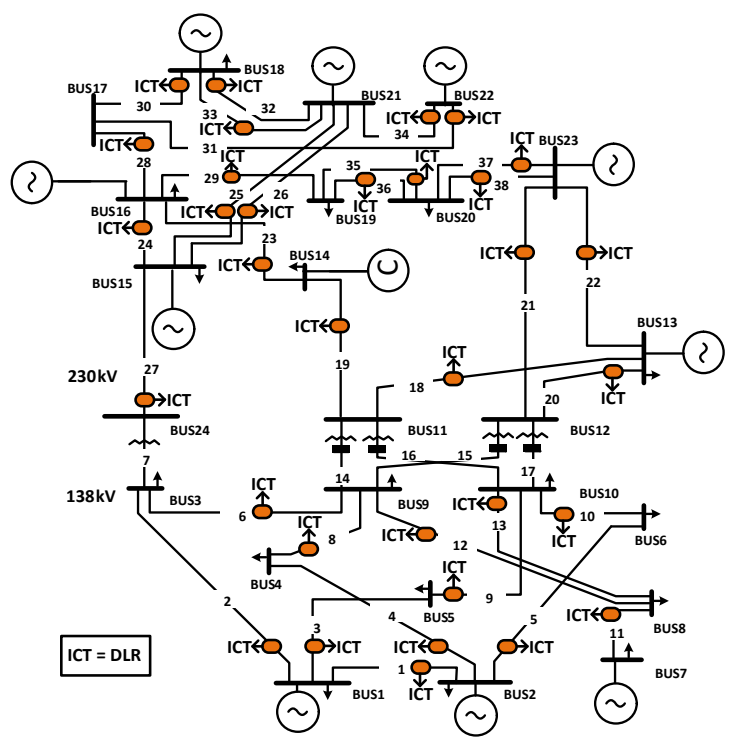

Fig. 4. Implementation of ICT technologies in IEEE 24 Bus RTS.

TABLE I. CONDUCTOR Properties Data Modelled

\begin{tabular}{|l|c|c|c|c|c|}
\hline \multicolumn{1}{|c|}{ Name } & $\begin{array}{c}\boldsymbol{R}_{75 \boldsymbol{C}} \\
(\mathbf{\Omega} / \mathbf{k m})\end{array}$ & $\begin{array}{c}\boldsymbol{X} \\
(\boldsymbol{\Omega} / \mathbf{k m})\end{array}$ & $\begin{array}{c}\boldsymbol{B} \\
(\mathbf{S} / \mathbf{k m})\end{array}$ & $\begin{array}{c}\boldsymbol{D} \\
(\mathbf{m m})\end{array}$ & $\begin{array}{c}\boldsymbol{I} \\
(\boldsymbol{A})\end{array}$ \\
\hline Upas (138kV OHL) & 0.11057 & 0.45435 & $3.392 \cdot 10^{-6}$ & 24.7 & 1000 \\
\hline Araucaria (230kV OHL) & 0.05021 & 0.43381 & $3.890 \cdot 10^{-6}$ & 37.3 & 1689 \\
\hline XLPE-800 (138kV UGC) & $0.02833^{*}$ & 0.11592 & $6.409 \cdot 10^{-5}$ & 85 & 1035 \\
\hline *The resistance for the cable is at 90C
\end{tabular}

A $138 \mathrm{kV}$ single-core unarmored XLPE UGC with $800 \mathrm{~mm}^{2}$ cross-area copper conductor is utilized for the low voltage area of the IEEE-RTS. The UGC has an $85 \mathrm{~mm}$ outer diameter and a $34 \mathrm{~mm}$ conductor diameter. Its XLPE thickness is $16 \mathrm{~mm}$ with a PVC oversheath thickness of $3.4 \mathrm{~mm}$.

All UGCs are assumed to be buried directly at a depth of $\ell=1.5 \mathrm{~m}$ with a constant $\rho_{T}=1 \mathrm{~km} / \mathrm{W}$ soil thermal resistivity throughout the simulation year. The selected UGC has a SLR $_{\text {UGC }}$ of $1023 \mathrm{~A}$ which is calculated using (2) based on a $25^{\circ} \mathrm{C}$ ambient soil temperature $\theta_{a}$ and a maximum $90^{\circ} \mathrm{C}$

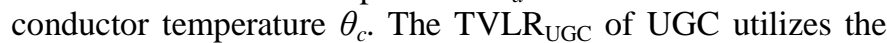
soil temperature data of year 2014 at a depth of 28 to $100 \mathrm{~cm}$ in
UK according to the ERA interim dataset from the ECMWF [19].

\section{B. Modelling Scenarios}

Seven different scenarios, shown in Table II are employed to investigate the impact of network reliability due to TVLRICT failures. The initial three scenarios are modelled to capture the ICT failures on OHL networks while the last four scenarios are modelled to capture the impact of the ICT failures on OHLs and UGCs networks.

All the ICT components within the network are modelled with identical failure and repair rates from [20]. Scenarios with OHLs networks, $\lambda_{O H L}$ and $\mu_{O H L}$ are obtained from [17]. However, for scenarios with UGCs, $\lambda_{\mathrm{UGC}}=\lambda_{\mathrm{OHL}}, \mu$ is calculated according to (3), where $\ell$ is the UGC length in miles. UGCs scenarios with different failure rates than OHLs are modelled according to (4).

$$
\begin{gathered}
\mu_{U G C}=11.5+1.5 \times \ell[\text { hours }] \\
\lambda_{U G C}=\left(\mu_{O H L} / \mu_{U G C}\right) \times \lambda_{O H L}[\text { outages } / y r]
\end{gathered}
$$

\begin{tabular}{|c|c|c|c|c|c|c|}
\hline & \multicolumn{2}{|c|}{$\begin{array}{c}\text { Network } \\
\text { Configuration } \\
\end{array}$} & \multirow{2}{*}{$\begin{array}{l}\text { TVLR- } \\
\quad I C T\end{array}$} & \multirow{2}{*}{$\begin{array}{l}\lambda_{T V L R-I C T} \\
(\text { occ } / \mathrm{hr})\end{array}$} & \multirow{2}{*}{$\begin{array}{l}\mu_{T V L R-I C T} \\
\quad(\boldsymbol{h r})\end{array}$} & \multirow{2}{*}{$\begin{array}{c}\lambda_{\text {Lines }} \\
(\text { occ/hr })\end{array}$} \\
\hline & $138 \mathrm{kV}$ & $230 \mathrm{kV}$ & & & & \\
\hline Sc-1 & OHLs & OHLs & $\mathrm{Ni}$ & $\mathrm{Ni}$ & $\mathrm{Ni}$ & $\lambda_{U G C}=\lambda_{O H L}$ \\
\hline Sc-2 & OHLs & OHLs & All Lines & 0 & 0 & $\lambda_{U G C}=\lambda_{O H L}$ \\
\hline $\mathrm{Sc}-3$ & OHLs & OHLs & All Lines & 0.0009 & 2.5 & $\lambda_{U G C}=\lambda_{O H L}$ \\
\hline Sc-4 & UGCs & OHLs & $\mathrm{Ni}$ & $\mathrm{Ni}$ & $\mathrm{Ni}$ & $\lambda_{U G C}=\lambda_{O H L}$ \\
\hline Sc-5 & UGCs & OHLs & All Lines & 0 & 0 & $\lambda_{U G C}=\lambda_{O H L}$ \\
\hline Sc-6 & UGCs & OHLs & All Lines & 0.0009 & 2.5 & $\lambda_{U G C}=\lambda_{O H L}$ \\
\hline Sc-7 & UGCs & OHLs & All Lines & 0.0009 & 2.5 & $\lambda_{U G C}$ from (4) \\
\hline
\end{tabular}

TABLE II. MODELING SCENARIOS OF TVLR-ICT

\section{NETWORK RESULTS \& ANALYSIS}

The network is assessed based on the proposed methodology at two different stages: firstly considering the impact of ICT failures on TVLR OHL networks and secondly considering the impact of ICT failures on both TVLR transmissions (OHLs) and TVLR distribution (UGCs) networks. This allows separating the benefit of different lines rating mechanisms against the impact of the unavailability of the ICTs required for the TVLR.

\section{A. System assessment on TVLR OHLs networks}

The computed output indices that describe the overall network performance are shown in Table III. By comparing the results for ENAL for Sc-1, Sc-2 and Sc-3 network losses are almost unaffected.

The Implementation of TVLR-ICT on all OHLs in Sc-2 decreases the duration of load curtailment by approximately $22 \%$ compared to the base case scenario ( $\mathrm{Sc}-1)$. This is mainly because the extra transmission capacity provided by the TVLR provides more flexible restoration paths once a failure has occurred. Consequently, the restoration times of load curtailment (EDLC) are reduced.

It is clearly shown in Table III that Sc-1 and Sc-2 contain similar values of EFLF. However their impact within the 
network is completely different. This can be seen from the distinct values of the EFLC index, which refers to the failures that solely provoke load shedding. Thus, only $10 \%$ of the total failures occurred under Sc-1 (80 Occ/yr) can be considered as critical. Sc-2 has less critical failures (6 Occ/yr) owing to the implementation of TVLR-ICT in all lines of the system. This also affects the EENS with an approximate 9\% reduction in Sc2 when compared to that of Sc-1.

TABLE III. CALCULATED INDICES With ONLY OHL IN THE NETWORK

\begin{tabular}{|c|c|c|c|c|c|c|}
\hline & $\begin{array}{c}\text { ENAL } \\
\text { MWh/yr }\end{array}$ & $\begin{array}{c}\text { EDLC } \\
\text { h/yr }\end{array}$ & $\begin{array}{c}\text { EFLC } \\
\text { Occ/yr }\end{array}$ & $\begin{array}{c}\text { EENS } \\
\text { MWh/yr }\end{array}$ & $\begin{array}{c}\text { EFLF } \\
\text { Occ/yr }\end{array}$ & $\begin{array}{c}\text { EFICTF } \\
\text { Occ/yr }\end{array}$ \\
\hline Sc-1 & 396 & 96 & 8 & 6761 & 80 & 0 \\
\hline Sc-2 & 395 & 74 & 6 & 6143 & 83 & 0 \\
\hline Sc-3 & 395 & 81 & 8 & 6343 & 82 & 850 \\
\hline
\end{tabular}

The benefit of implementing TVLR-ICT on power network can already be observed with the comparison of Sc-1 and Sc-2. However, the impact of ICT failures on TVLR of OHLs can be seen in Sc-3. The transmission losses and the line failures are virtually identical in Sc-2 and Sc-3. However an increase in EDLC is achieved in Sc-3 in comparison to Sc-2. This is expected due to the fact that the ICT failures in $\mathrm{Sc}-3$ reduce the lines' ampacity and therefore, less transmission capacity is available specifically during line failures. In addition critical failures (EFLC) are more frequent in Sc-3 and their impact in load curtailment is obvious (Table III) compared to Sc-2. This is also indicated with the EENS value of Sc-3, which is $3.5 \%$ greater than the EENS of Sc-2.

The inclusion of TVLR helps the system to be more efficient through the reduction of the duration of load curtailment and energy not supplied inter alia. Consequently, as expected, the inclusion of TVLR improves the overall system performance. However, there are fewer critical failure (against lines failures) events in the network. It is, thus, crucial to consider the TVLR-ICT failures as the criticality of these few failures is increased due to increased loading of the lines (as a result of the inclusion of smart technologies).

\section{B. System assessment on TVLR OHLs and UGCs networks}

The failures of ICTs implemented on TVLR for both OHLs and UGC are modelled in Sc-6 and Sc-7, (while Sc-4 and Sc-5 do not consider ICT failures). These capture the impact of the ICT failures when UGCs are implemented at a low voltage network (instead of OHLs). The computed outputs of these scenarios are shown in Table IV.

TABLE IV. CALCULATED INDICES With OHL \& UGC IN THE NETWORK

\begin{tabular}{|c|c|c|c|c|c|c|}
\hline SCN & $\begin{array}{c}\text { ENAL } \\
\text { MWh/yr }\end{array}$ & $\begin{array}{c}\text { EDLC } \\
\text { h/yr }\end{array}$ & $\begin{array}{c}\text { EFLC } \\
\text { Occ/yr }\end{array}$ & $\begin{array}{c}\text { EENS } \\
\text { MWh/yr }\end{array}$ & $\begin{array}{c}\text { EFLF } \\
\text { Occ/yr }\end{array}$ & $\begin{array}{c}\text { EFICTF } \\
\text { Occ/yr }\end{array}$ \\
\hline Sc-4 & 368 & 390 & 19 & 34114 & 69 & 0 \\
\hline Sc-5 & 368 & 317 & 18 & 29751 & 69 & 0 \\
\hline Sc-6 & 367 & 359 & 31 & 31298 & 71 & 964 \\
\hline Sc-7 & 367 & 162 & 25 & 12784 & 60 & 998 \\
\hline
\end{tabular}

The benefits of implementing TVLR on UGCs and OHLs against SLR can be observed in Fig. 5, which illustrates the simulation results of the annual lines ratings of UGCs and OHLs. The TVLR $\mathrm{UGC}_{\mathrm{U}}$ and $\mathrm{TVLR}_{\mathrm{OHL}}$ ratings are given in pu in monthly basis. The SLR $\mathrm{OHL}_{\mathrm{OH}}$ and $\mathrm{SLR}_{\mathrm{UGC}}$ are indicated with the black line and considered identical. This SLR is the base used for the pu ratings.

By observing the computed results of lines' ampacity in Fig. 5, it can be seen that TVLR $_{\text {OHL }}$ provides on average $26 \%$ more transmission capacity than TVLR $\mathrm{UGC}_{\mathrm{UG}}$ and approximately

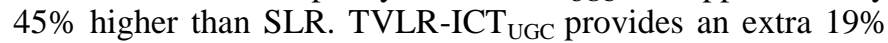
ampacity only when compared with STR. This is due to UGC ratings mainly being related with soil temperature which does not have much variation along the time. However, the greatest TVLR-ICT $\mathrm{OHL}_{\mathrm{OH}}$ capacities are achieved during the windiest and coldest months of the year (February, March and April) as expected.

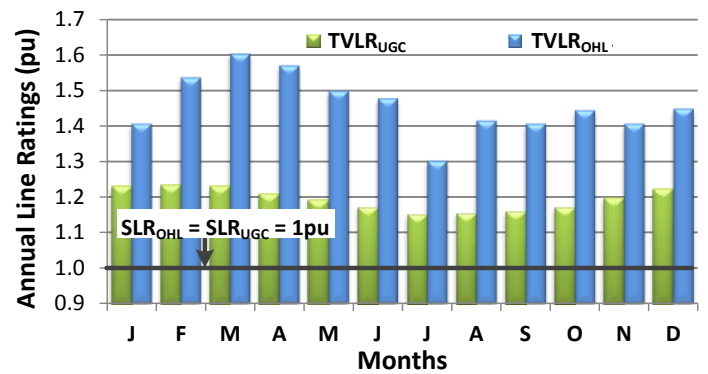

Fig. 5. Annual line ratings in pu of UGCs and OHLs networks.

By examining the performance of the network under Sc-5 against that of Sc-4 it is obvious (Fig 5) that the inclusion of TVLR-ICT on the power network helps to increase the network adequacy during emergency conditions. As a result a reduction of approximately $13 \%$ of EENS is achieved in Sc-5, even though both scenarios (Sc-4 and Sc-5) result in similar critical failures $(\approx 18 \mathrm{Occ} / \mathrm{yr})$. In addition, the real benefit of TVLR can be seen by means of the EDLC index, which drops roughly $19 \%$ in Sc-5 against Sc-4. This is due to the increased loading the TVLR provides which then results in increased operational flexibility during the failures.

By observing the calculated values of EENS (Fig 6) the one reached in Sc-6 is higher than the one obtained in Sc-5. In addition, critical failures are more frequent in Sc-6, and therefore their impact in load curtailment is higher than the failures occurred in Sc-5. This is also indicated by the duration of load curtailment in Sc-6, which is greater than the value obtained in Sc-5. This is due to the fact that the ICTs failures (964 Occ/yr) occurred in Sc-6 additionally provoke load curtailment since lines ampacities are reduced, so EFLC and EDLC are highly affected. However due to the extra transmission capacity provided by TVLR-ICT to the system their failures do not provoke greater impacts.

As shown in Fig 6, Sc-7 contains roughly $15 \%$ fewer line failures (red bars) than Sc-5 and Sc-6. ICT failures obtained in Sc-7 are $3.5 \%$ more than Sc-6 and its EENS (Sc-7) is significantly reduced around $57 \%$ and $60 \%$ compared to Sc-5 and Sc-6 respectively. The reduction of the EDLC in Sc-7, which is approximately half of the value obtained for the remaining scenarios with UGCs is also due to the reduced failure rate of UGCs. As a result, the increased network adequacy under Sc-7 reduces all network performance metrics making it the best performing scenario when UGCs are implemented within the system. 


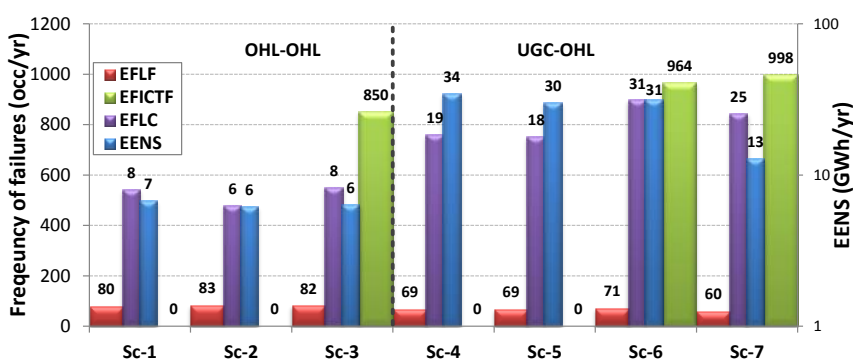

Fig. 6. Network performance indices.

When comparing the scenario Sc-3 (only OHLs) with Sc-6 (OHLs and UGCs) a significant increase of EENS is observed. On average, approximately 4 times more EENS is produced due to the UGCs. This mainly occurred, because the extensive amount of time required to repair cables in comparison to that for OHLs. Repair rate is the most contributing factor of incrementing the EENS in scenarios with UGCs.

Considering failure rate, the fact that this resulted as identical for UGCs and OHLs is not common practice. In reality, UGCs are expected to fail less often than OHLs. However, when the UGCs failure rates are reduced (Sc-7) and TVLR-ICTs are implemented still not large benefits are achieved in comparison to Sc-3. This is because when ICTs fail the EDLC and EENS are severely increased by a factor of two (comparing Sc-7 and Sc-3), principally due to the repair time of UGCs.

By observing the calculated values of EFLF in Fig. 6, it can be seen that all scenarios without and with UGCs have similar performance among them, since there is no change on the network line reliability characteristics (i.e., failure and repair rates). Apart from Sc-7 (failure rate reduction) that results in slightly less line failures per year than all other scenarios as it was expected, every other scenario has very similar performance providing evidence for the results validity.

\section{CONCLUSIONS}

A methodology has been developed to allow a realistic implementation of ICTs unavailability into the power network. This is achieved through the improved modelling of the branch components allowing the inclusion of TVLR instrumentation in both OHLs and UGCs and its overall effect on network reliability.

From the analysis of the IEEE-RTS 96 it is clear that ICTs failures do not have a major impact on the system. This however, is due to the network layout and the voltage constraints dominating the thermal constraints on the 24-Bus RTS. The inclusion of TVLR-ICT relaxes the thermal constraints thus resulting in a small impact of ICT failures on this network. However, this may not be true on a different network. This is obvious from the resulted EENS due to the replacement of OHL for UGC even when a low UGC failure rate is implemented $(\mathrm{Sc}-7)$.

The ICT failures on TVLR OHLs and UGC networks increase the frequency and duration of the load curtailment reducing therefore its reliability.

\section{REFERENCES}

[1] W. Yik-Chung, C. Long-Fung, L. King-Shan, and P. W. T. Pong, "Efficient Communication of Sensors Monitoring Overhead Transmission Lines," Smart Grid, IEEE Transactions on, vol. 3, pp. 1130-1136, 2012.

[2] K. M. Klein, P. L. Springer, and W. Z. Black, "Real-time ampacity and ground clearance software for integration into smart grid technology," in Power and Energy Society General Meeting, 2011 IEEE, 2011, pp. 1-11.

[3] M. Panteli and D. S. Kirschen, "Assessing the effect of failures in the information and communication infrastructure on power system reliability," in Power Systems Conference and Exposition (PSCE), 2011 IEEE/PES, 2011, pp. 1-7.

[4] D. Kirschen and F. Bouffard, "Keeping the lights on and the information flowing," Power and Energy Magazine, IEEE, vol. 7, pp. 50-60, 2009.

[5] B. Falahati, F. Yong, and M. J. Mousavi, "Reliability Modeling and Evaluation of Power Systems With Smart Monitoring," Smart Grid, IEEE Transactions on, vol. 4, pp. 1087-1095, 2013.

[6] D. M. Greenwood and P. C. Taylor, "Investigating the Impact of RealTime Thermal Ratings on Power Network Reliability," Power Systems, IEEE Transactions on, vol. 29, pp. 2460-2468, 2014.

[7] Y. Jin, B. Xuefeng, D. Strickland, L. Jenkins, and A. M. Cross, "Dynamic Network Rating for Low Carbon Distribution Network Operation: A U.K. Application," Smart Grid, IEEE Transactions on, vol. 6, pp. 988-998, 2015.

[8] E. Cloet and J. L. Lilien, "Uprating Transmission Lines through the use of an innovative real-time monitoring system," in Transmission and Distribution Construction, Operation and Live-Line Maintenance (ESMO), 2011 IEEE PES 12th International Conference on, 2011, pp. 16.

[9] L. Qi, M. Musavi, and D. Chamberlain, "Overhead conductor thermal rating using neural networks," in Smart Measurements for Future Grids (SMFG), 2011 IEEE International Conference on, 2011, pp. 139-142.

[10] F. Xianyong and M. J. Mousavi, "Study of intelligent overloading in power delivery systems," in PES General Meeting | Conference \& Exposition, 2014 IEEE, 2014, pp. 1-5.

[11] S. C. E. Jupe, D. Kadar, G. Murphy, M. G. Bartlett, and K. T. Jackson, "Application of a dynamic thermal rating system to a $132 \mathrm{kV}$ distribution network," in Innovative Smart Grid Technologies (ISGT Europe), 2011 2nd IEEE PES International Conference and Exhibition on, 2011, pp. 18.

[12] F. M. a. C. Q. E.M. Carlini, "Methodologies to Uprate and Overhead Line. Italian TSO Case study," Journal of Electrical Systems, 2013.

[13] Y. C. Liang and Y. M. Li, "On-line dynamic cable rating for underground cables based on DTS and FEM," WSEAS Trans. Cir. and Sys., vol. 7, pp. 229-238, 2008.

[14] K. Kopsidas, C. Tumelo-Chakonta, and C. Cruzat, "Power Network Reliability Evaluation Framework Considering OHL Electro-Thermal Design," IEEE Transactions on Power Systems, vol. PP, pp. 1-9, 2015.

[15] "IEEE Standard for Calculating the Current-Temperature Relationship of Bare Overhead Conductors," IEEE Std 738-2012 (Revision of IEEE Std 738-2006 - Incorporates IEEE Std 738-2012 Cor 1-2013), pp. 1-72, 2013.

[16] "IEC Standard 60287-2-1: Calculation of the continuous current rating of cables (100 \% load factor)," ed: International Electrotecnical Commission, 2001.

[17] P. Wong, P. Albrecht, R. Allan, R. Billinton, Q. Chen, C. Fong, et al., "The IEEE Reliability Test System-1996. A report prepared by the Reliability Test System Task Force of the Application of Probability Methods Subcommittee," Power Systems, IEEE Transactions on, vol. 14, pp. 1010-1020, 1999.

[18] W. Observatory. Weather Data, University of Manchester Available: http://www.cas.manchester.ac.uk/restools/whitworth/data/index.html

[19] ECMWF. (2014). ERA Interim dataset: soil temperature. Available: http://apps.ecmwf.int/datasets/data/interim-full-daily

[20] "<Reliability Assessment of Time-Dependent Systems.pdf $>$." 
